Titulo do Trabalho

\title{
Programa de Gestão de Resíduos - Poli USP Recicla
}

Nome do Autor Principal

Welson G. Barbosa Jr

Nome da Coautora

Amanda da Silva EI-Bachá

Instituição ou Empresa

Poli USP Recicla

Instituição de Fomento

Escola Politécnica da USP

E-mail de contato

poli.usp.recicla@poli.usp.br

RESUMO: O Programa de Gestão de Resíduos da Escola Politécnica da USP, denominado Poli USP Recicla, foi criado em 2006 com o objetivo de transformar a gestão sustentável de todos os resíduos gerados nas diversas atividades da Poli em uma extensão natural de suas atividades. O programa é delineado em consonância com as diretrizes da Escola e busca cumprir na íntegra a legislação vigente, além de trabalhar com o conceito de resíduo mínimo, evitando a confecção de impressos descartáveis e fazendo uso intenso da mídia eletrônica e de placas permanentes. O Poli Recicla administra cinco projetos principais: Gestão de Lâmpadas Fluorescentes; Gestão de Pilhas e Baterias; Gestão de Resíduos Laboratoriais; Gestão de Toners/Cartuchos; Coleta Seletiva de Resíduos Não Perigosos. A equipe do Poli Recicla continua com o processo de consolidação e ampliação destes projetos, com envolvimento dos funcionários, docentes e alunos da Escola, além dos funcionários terceirizados da limpeza. O programa teve reconhecimento institucional e foi solicitado a auxiliar na implantação dos processos em instituições externas, convidado para apresentações em eventos de gestão ambiental, além de auxiliar outras unidades da USP.

Palavras chave: Gestão Sustentável. Resíduos. Reciclagem. 


\section{INTRODUÇÃO}

O Programa Poli Recicla integra a Escola Politécnica (Poli) à Superintendência de Gestão Ambiental da USP, que se dedica a promover a gestão sustentável dos resíduos dentro da USP. O Programa é gerenciado por um grupo da comunidade politécnica, que inclui alunos, funcionários e professores, mas está aberto à participação da comunidade.

Dado o tamanho da Escola Politécnica, que ocupa um total de nove prédios por onde passam mais de 17000 pessoas por dia, e a complexidade dos resíduos gerados, que incluem desde resíduos típicos de escritório até resíduos perigosos de diferentes laboratórios, fez-se necessária a criação de um programa de gestão de resíduos.

Foi neste contexto que nasceu o Programa Poli Recicla, no segundo semestre de 2006. Em seu início, foi realizada uma análise da situação momentânea e das exigências impostas pela Política Estadual de Resíduos Sólidos do Estado de São Paulo e de outras legislações pertinentes. Esse diagnóstico abriu, portanto, caminho para a discussão de práticas de gestão e de participação da comunidade.

Atualmente, o Programa Poli Recicla tem em atividade cinco processos principais: Gestão de Lâmpadas Fluorescentes; Gestão de Pilhas e Baterias; Gestão de Resíduos Laboratoriais; Gestão de Toners/Cartuchos; Coleta Seletiva de Resíduos Não Perigosos.

Todas as etapas dos projetos são amplamente divulgadas à comunidade politécnica através de ferramentas de divulgação interna, tais como e-mail (Informativo da Poli), intranet, sites da Poli e do Poli Recicla, redes sociais da Poli, jornais do grêmio e dos centros acadêmicos, jornais da USP etc. O processo de implantação de todos os projetos envolveu análise criteriosa de produtos e serviços, assim como treinamento de todos os envolvidos.

\section{OBJETIVO GERAL}

O Poli USP Recicla tem, como objetivo principal, gerir de forma sustentável os resíduos gerados nas diversas atividades da Escola Politécnica. O programa é delineado em consonância com as diretrizes da Escola, buscando cumprir na íntegra a legislação vigente e desenvolver novas soluções mais avançadas. 


\section{OBJETIVOS ESPECÍFICOS}

Para cada projeto gerenciado pelo Poli Recicla existem objetivos específicos:

- Gestão de Lâmpadas Fluorescentes e Mistas: Eliminar por completo o descarte de lâmpadas fluorescentes e mistas em locais inadequados.

- Gestão de Pilhas e Baterias: Destinar corretamente os resíduos de pilhas e baterias gerados pela comunidade politécnica.

- Gestão de Resíduos Laboratoriais: Consolidar um levantamento de todos os resíduos laboratoriais da Escola, identificando os tipos, a quantidade, o estado físico, o estado das embalagens, a periodicidade da geração e sua localização.

- Gestão de Toners/Cartuchos: Garantir que os cartuchos/toners recolhidos na POLI sejam transportados, manuseados e tratados por empresas especializadas.

- Coleta Seletiva de Resíduos Não Perigosos: Reduzir continuamente o índice de mistura entre resíduos recicláveis e não recicláveis, garantir a correta destinação do resíduo reciclável para uma cooperativa e treinar os funcionários envolvidos.

\section{METODOLOGIA}

Cada projeto do Poli Recicla apresenta uma metodologia com suas particularidades, porém todos apresentam uma mesma estrutura de base. O processo de gestão é sempre elaborado pela identificação dos pontos de coleta, treinamentos, aquisição de coletores e contratação de serviço de coleta, descontaminação e destino final dos resíduos por empresa especializada. Os alunos monitores têm a responsabilidade de fiscalizar as condições dos coletores, as quantidades de resíduo acumulado e a disposição destes nos coletores até sua destinação final.

\section{RESULTADOS}

\subsection{Gestão dos Resíduos Perigosos}

\subsubsection{Lâmpadas Fluorescentes}

Classificadas como resíduo perigoso pela NBR 10.004/2004, as lâmpadas fluorescentes necessitam de tratamento específico. De dezembro de 2010 a dezembro de 
2013, foram enviadas para descontaminação 30.000 unidades (3.414 só em 2013) sendo que $12.454(41,5 \%)$ não saíram do almoxarifado, sendo provenientes de outras fontes.

O Poli Recicla utiliza quatro indicadores para medir esse processo:

(a) Porcentagem de lâmpadas provenientes de outras fontes.

(b) A massa de mercúrio que foi recuperada, considerando, segundo a Apliquim Brasil Recicle, que cada lâmpada fluorescente tubular possua, em média, 8 mg de mercúrio metálico.

(c) População com sua água de abastecimento prejudicada, durante uma semana, caso o mercúrio recuperado no indicador (a) fosse lançado diretamente no sistema. Neste caso considerou-se o consumo per capita de 250 litros diários e o padrão de potabilidade para o mercúrio da Portaria MS N518/2004.

(d) Valor gasto com a descontaminação, considerando um custo médio de $\mathrm{R} \$ 0,50$ por lâmpada.

Assim, os valores levantados, até dezembro de 2013 foram:

(a) 41,5\% das lâmpadas não são provenientes do almoxarifado.

(b) Recuperação de 240,0 gramas de mercúrio metálico;

(c) População de 137 mil habitantes;

(d) $R \$ 15.000,00$ gastos para atingir este grande benefício ao meio ambiente.

\subsubsection{Pilhas e Baterias}

Este resíduo também é classificado como perigoso pela ABNT NBR 10.004/2004, ou seja, também necessita de tratamento específico por liberarem ácidos e metais pesados. Durante o ano de 2013 foram coletados $300 \mathrm{~kg}$ de pilhas e baterias. Ao longo de seis anos de projeto, já foram coletadas mais de 3,9 toneladas. Em Outubro de 2012, o Poli Recicla fez uma parceria com o CEDIR/CCE, e desde então o descarte de pilhas tem sido feito por eles, eliminando os custos do processo da Poli-USP.

\subsubsection{Resíduos Laboratoriais}

Este resíduo apresenta características que os colocaram na Classe I da NBR 10.004. São elas: inflamabilidade, corrosividade, reatividade, toxicidade e/ou 
patogenicidade. A quantidade de resíduos laboratoriais descartados der 2009 a dezembro de 2013 é da ordem de 17,823, com custo estimao em $\mathrm{R} \$ 80.000,00$.

\subsection{Gestão dos Resíduos não Perigosos}

\subsubsection{Coleta Seletiva nos Prédios da POLI}

A Gestão de Resíduos não perigosos (Classe II pela ABNT NBR 10.004/2004) teve início em 2008. Atualmente, todos os prédios da Escola contam com coletores internos, externos e quadros informativos. Os coletores externos são onde os funcionários da limpeza depositam os resíduos acumulados em todos os coletores internos. Em 2013 foram coletadas mais de 58 toneladas de resíduos de Classe II.

Para medição dos resultados desse processo, foi criada a "Semana dos Indicadores" com periodicidade semestral. Portanto, duas vezes ao ano, a equipe do Poli Recicla, durante uma semana retira amostras de diversos coletores para pesar a quantidade de lixo comum entre os recicláveis e a quantidade de resíduo reciclável no meio do lixo comum. Este indicador baliza planos de ação para a informação à comunidade. Em 2013, encontramos 4,5\% de não recicláveis entre os recicláveis e 11,5\% de recicláveis no lixo comum. Esses números indicam bons resultados, porém constitui um alerta sobre a necessidade de campanhas continuadas junto aos usuários.

\subsubsection{Cicléias - Coleta Seletiva aberta à comunidade}

Em 2008 o Poli Recicla aderiu à ação do Programa USP Recicla de instalação de pontos de coleta seletiva, dentro do convênio com a Limpurb. Foram instaladas quatro "Cicléias". Deste então, vem sendo registrada a coleta semanal de 10 mil litros de material para triagem e destinação correta.

\subsection{Outros Resíduos}

\subsubsection{Gestão de toners e cartuchos usados ou vencidos}

Toners e cartuchos de impressão usados ou vencidos devem ser descartados de maneira adequada, pois podem contaminar o meio ambiente. $O$ material utilizado nos departamentos da Escola Politécnica é encaminhado ao Poli Recicla, que faz a devolução aos fabricantes, caracterizando um processo pioneiro de Logística Reversa. Esta logística 
é realizada desde 2009, tendo sido devolvidas, desde o início do programa, aproximadamente, 2.700 unidades.

\subsubsection{Gestão de resíduos de construção civil}

Foi sugerido pelo Poli Recicla e acatado pelos gestores de contrato do Serviço de Manutenção e Obras da Poli a inclusão de um adendo nos contratos com os prestadores de serviços de obras no sentido de contemplar nesses contratos a gestão de resíduos de construção civil para atender os critérios exigidos nas legislações vigentes.

\subsection{Doação de canecas duráveis}

Em 2012, o Poli Recicla continuou a distribuir canecas duráveis para serem utilizadas nos restaurantes universitários a fim de reduzir a utilização de copos descartáveis. Até dezembro de 2013, 3.027 pessoas nos procuraram para retirada da caneca. O Poli Recicla divulga que possui canecas para serem distribuídas e aguarda o contato dos interessados, que devem retirá-las no local. No ato da retirada da caneca, o interessado recebe breves informações sobre o programa do Poli Recicla e assina uma folha de controle.

\subsection{Treinamentos, Palestras e Reuniões}

Em 2013, foram realizados, o quinto e sexto treinamento sobre resíduos não perigosos para a equipe de limpeza, com grande adesão de participantes e com significativa melhoria nas práticas da gestão de resíduos por todos os envolvidos. Nesta edição compareceram 106 funcionários, caracterizando uma adesão de $97 \%$.

No final de ano, a equipe do Poli Recicla reuniu zeladores, administradores e gestores dos prédios, além de secretários(as), assistentes e diretores(as) para apresentar os novos processos, os indicadores dos processos já conhecidos, recolher sugestões, críticas, ideias e traçar objetivos e metas para o ano seguinte. Com este trabalho buscamos integrar o nosso trabalho com o cotidiano da Escola Politécnica.

\subsection{Divulgação}

Em 2012, finalizou-se a migração do site do Poli Recicla para o novo domínio do servidor do site da Escola Politécnica. Após um breve treinamento com o Serviço de 
Informática, a equipe do Poli Recicla foi capacitada para realizar de forma autônoma suas publicações e divulgações, auxiliando a cumprir a meta de não realizar divulgações impressas. Além disso, será nesta nova plataforma que o Sistema de Gestão de Resíduos Laboratoriais será desenvolvido a partir do modelo já existente.

\subsection{Atendimento ao Público}

O Poli Recicla continua a realizar de modo satisfatório e com crescente demanda, os atendimentos às solicitações externas, realizadas pelos mais diversos públicos sobre diferentes assuntos. Essa demanda se dá $90 \%$ através do site (www.poli.usp.br/recicla) e $10 \%$ através de ligações telefônicas.

Além de ser procurado pelo público externo, ocorreram diversas solicitações internas. para disseminar suas boas práticas na gestão de resíduos na Fundação de Apoio à USP - FUSP, Faculdade de Ciências Farmacêuticas da USP, Coordenadoria do Campus da Capital - COCESP, Faculdade de Economia, Administração e Contabilidade da USP.

\subsection{Programa de Educação Ambiental}

No segundo semestre de 2012, a equipe do Poli Recicla desenvolveu um plano de trabalho para realizar um programa de educação ambiental em instituições públicas de ensino em comunidades carentes. O projeto aconteceu durante todo o ano de 2013 na E.E Prof. Renato de Arruda Penteado onde foram disseminadas boas práticas de gestão de resíduos em classes menos favorecidas da sociedade e capacitamos jovens a serem multiplicadores do conhecimento em suas comunidades.

\section{CONSIDERAÇÕES FINAIS}

Após pouco mais de sete anos de atividades, o Poli Recicla avançou na sua consolidação e tornou-se referência de gestão de resíduos para diversas universidades brasileiras, sendo constantemente requisitado para auxiliar na implantação de gestões de resíduos em outras entidades.

A estratégia de centrar esforços na criação de infraestrutura para a gestão, associada a treinamento dos profissionais afetados pela nova forma de trabalho, revelouse eficaz, como demonstram os resultados do programa de coleta. Mas o Poli Recicla não 
pretende parar por aí. Para garantir que haja uma melhoria contínua, é necessário que sempre ocorram outros treinamentos para manter todos os envolvidos atualizados.

As planilhas de controle e os indicadores criados pela equipe foram fundamentais para tornar o trabalho fácil de ser mensurado e acompanhado. Além disso, o apoio que a Diretoria da Escola tem dispensado ao Poli Recicla também foi de grande importância para que o programa atingisse suas metas.

O gerenciamento de resíduos sólidos, mais que uma responsabilidade legal, é uma necessidade social e ambiental premente. A Escola Politécnica como educadora e formadora de opinião deve capacitar seus alunos, futuros profissionais no mercado de trabalho, a desenvolverem suas atividades de forma mais limpa e ambientalmente sustentável. A Escola deve, antes de tudo, servir de exemplo.

\section{REFERÊNCIAS}

ABNT. NBR 10.004/2004: Classificação de Resíduos Sólidos - elaborada em 1987, revisada em 2004.

Portaria MS N518/2004: Procedimentos e responsabilidades relativos ao controle e vigilância da qualidade da água para consumo humano e seu padrão de potabilidade.

Resoluções CONAMA 307, de 05.07.2002: Estabelece diretrizes, critérios e procedimentos para a gestão dos resíduos da construção civil.

Resolução CONAMA 348, de 16.08.2004: Altera a Resolução CONAMA n 307, de 5.07.2002, incluindo o amianto na classe de resíduos perigosos. 